\title{
Türk ve Ukraynadaki halk atasözlerinde kadin görüntüsü (dil karşilaştırmali özellikleri)
}

\section{Irina YUZVYAK}

Ukrayna Milli Bilimler Akademisi, A. Krimskiy Doğubilim Araştırma Enstitüsü

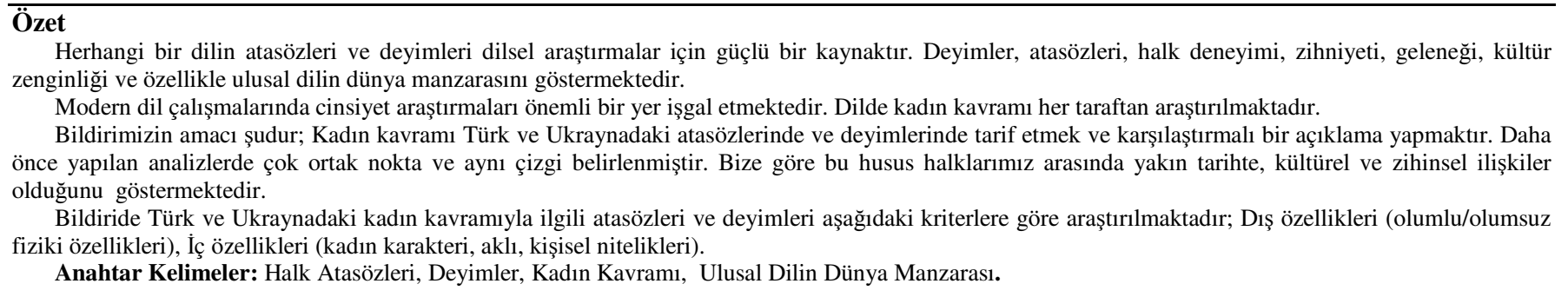

\section{Image of wowan in Turkish and Ukrainian proverbs and phraseologisms (language copmarable features)}

\begin{abstract}
Proverbs and idioms of any language is a powerful resource for linguistic researching. Idioms, proverbs show the folk experience, spirit, tradition, culture, wealth, and especially in view of the national language world model. In the modern language researching the gender studies have the one of the most inportant place. The concept of women are being investigated from the whole sides of language.

The aim of this paper is to research and the make a comparative description of concept of the woman in the Turkish and Ukrainian proverbs. How to shows the earlier analysis of this proverbs and idioms between Turks and Ukrainians are so much common features.

In the article Turkish and Ukraine proverbs and idioms related to the concept of woman being investigated by the following criterions: exterior features (positive/negative physical characteristics), internal characteristics (character, intellect, personal qualities).

Key Words: folk proverbs, idioms, concept of woman, national language world model.
\end{abstract}

\section{Türkçe'de atasözlerinin ve deyimlerin kavramı ve özellikleri}

Atasözleri ve deyimler halk zihniyeti, halkın kültür zenginliği ve özellikle dil özelliklerini çok net bir şekilde yansıtmaktadır. Herhangi bir dilde atasözleri dil araştırmaları için güçlü bir kaynaktır. Çünkü atasözleri ve deyimler kuşaktan kuşağa kaydedilen halk tecrübesini, geleneğini, adetlerini, kültürünü, estetik ve manevi değerlerini göstermektedir. Atasözlerinin ve deyimlerin dili manevi ve maddi kültürün izlerini taşımaktadır.

Atasözlerinin ve deyimlerin kavramı bir çok araştırmacı tarafından araştırılmaktadır.

\section{Atasözlerinin kavramı}

Atasözleri ve deyimlerinin en meşhur araştırmacından biri Asım Aksoy atasözlerinin kavramı şöyle tanımlamıştır; atasözleri, geniş halk yığınlarının yüzyıllar boyunca geçirdikleri denemelerden ve bunlara dayanan düşüncelerden doğmuşlardır. Bilim adamı atasözlerinin böyle özelliklerini sunmaktadır;
1. Atasözleri kalıplaşmış (klişe durumuna gelmiş) sözlerdir: her atasözu, belli bir kalıp içinde, belli sözcuklerle soylenmiş olan dönmüş bir biçimdir.

2. Atasözleri kısa ve özlüdür. Az sözcükle çok şey anlatır.

3. Atasözlerinin coğu bir, iki cümledir. Daha uzun olanları azdır (Aksoy, 2005: 3).

Araştırmacı Ö. Çobanoğlu atasözlerinin kavramını şöyle tanımlamıştır; atasözleri tarihîn, geçmişin bir aynasıdır. Tarihîn ve kültürün aynasıdır, çünkü atasözleri tarihîn içinde, tarihle beraber dogmuş, onunla beraber gelişmiş ve onunla beraber zamanımıza ulaşmıştır ve geleceğe doğru yol almaktadır (Çobanoğlu, 2004 : 17).

\section{Deyimlerin kavramı}

Deyimler - sabit ifadeler olarak halk geleneklerini, inançlarını, dini törenlerini, değerlerini, adetlerini, bilgilerini, kavramlarını, fikirlerini, davranış kalıplarını ve klişelerini çok net ve canlı bir şekilde yansıtmaktadır. Deyimler yaratıcı bilince aittir, o yüzden çevredeki ortamı betimlemiyor yorumluyordur. $\mathrm{Bu}$ nedenle onlar ulusal ve kültürel bilgi taşıyıcıları olarak kabul edilebilir.

Bize göre, deyimlerin başlıca özellikleri şunlardır;

1. Anlamsal bütünlük. 
2. Tasvir etme.

3. Anlam değişmezliği.

4. Anlatım / ifade gücü.

Deyim, araştırmacı Ömer Asım Aksoy’a göre: "Bir kavramı, bir durumu, ya çekici bir anlatımla ya da özel bir yapı içinde belirten ve çoğunun gerçek anlamlarında ayrı bir anlamı bulunan kalıplaşmış sözcük topluluğu ya da tümce" (Aksoy, 1988 : 52). Zeynep Korkmaz deyimi şöyle tanımlamıştır: gerçek anlamından farklı bir anlam taşıyan ve çekici bir anlatım özelliğine sahip olan kelime grubu (Korkmaz, 2010 : 66).

Deyimler, edebiyat ve halk bilimi açısından olduğu kadar dilbilim bakımından da önemli sözlerdir. Bu öğeler, dilin içyapısını, anlam özelliklerini, kullanımdan düşmüş kelimelerin etimolojik takibini kolaylaştırır. Deyimlere bakılarak dillerin kendine özgü yanları ortaya çıkarılabilir. $\mathrm{Bu}$ durum, milletlerin gerçekleri dile getirmedeki anlayış ve anlatış biçimini gösterir (Aksan, 2007 : 91).

Türk ve Ukraynadaki ulusal dünya dilinin manzarasında kadın kavramı

Modern dil çalışmalarında cinsiyet araştırmaları önemli bir yer işgal etmektedir ve bu dil araştırmalarına göre cinsiyet belirtisi bireyin konuşma davranışını etkilemektedir.

Kadının kullandığı dil erkeğin kullandığı dilden farklıdır.

Kadın kavramı bir toplumun kültürünün temel kavramlarından biridir. Kuşkusuz kadın kavramı Türk ve Ukrayna kültüründe önemli bir yere sahiptir. Ancak bazı sorularında cevabını bulmaya çalışmış bulunmaktayım. Mesela Bu iki ülkenin kültür ve dilinde kadının rolü nedir? Türkçe'de ve Ukraynaca'da nasıl yansıtılmaktadır? Türk ve
Ukrayna'daki atasözleri ve deyimlerde kadın kavramı nedir? Benzer ya da farklı taraflar var midır?

İlk olarak "kadın" kelimesini Türk ve Ukraynadaki sözlüklerde incelemek gerekmektedir. Büyük Türkçe Sözlükte "kadın" kelimesinin anlamlarını şu şekilde belirtmiştir; 1.Dişi cinsten erişkin insan, erkek veya adam karşıtı. 2. Evlenmiş kız. 3. Bayan anlamında kullanılan bir unvan. 4. Analı veya ev yönetimi bakımından gereken erdemleri olan. 5 Hizmetçi (BTS, 1863).

Ukrayna'daki Sözlükte "kadın” kelimesinin üç anlamı vardır; 1. Kadın cinsiyetli kişi. 2. Yetişkin kişi küçük kızın aksine. 3. Kocası olan (koca ile ilgili) evli kişi. Genel olarak evli kadın.

Kadın kavramını birçok sınıfa ayrımak mümkündür:

- yaşına göre (kız, kadın, yaşlı kadın vs.),

- evlilik durumuna göre (gelin, karl, avrat, yenge, kaynana, dul kadın,vs.),

- aile ilişkilerine göre (anne, ana, kız kardeş, abla, teyze vs.),

- toplumsal diğer unsurlarına göre (hanımefendi, hatun, vs.),

- sosyal rollerine göre (aşçı kadın, temizlikçi kadın, hemşire vs.),

- gizemcilik gücüne göre (büyücü) ve diş dünyaya göre (peri, cadl vs.). (Eşkenov 2007:15). İncelenen Ukraynadaki atasözleri ve deyimlerde kadın kavramı çok net bu diyagramda yansitilmaktadir;

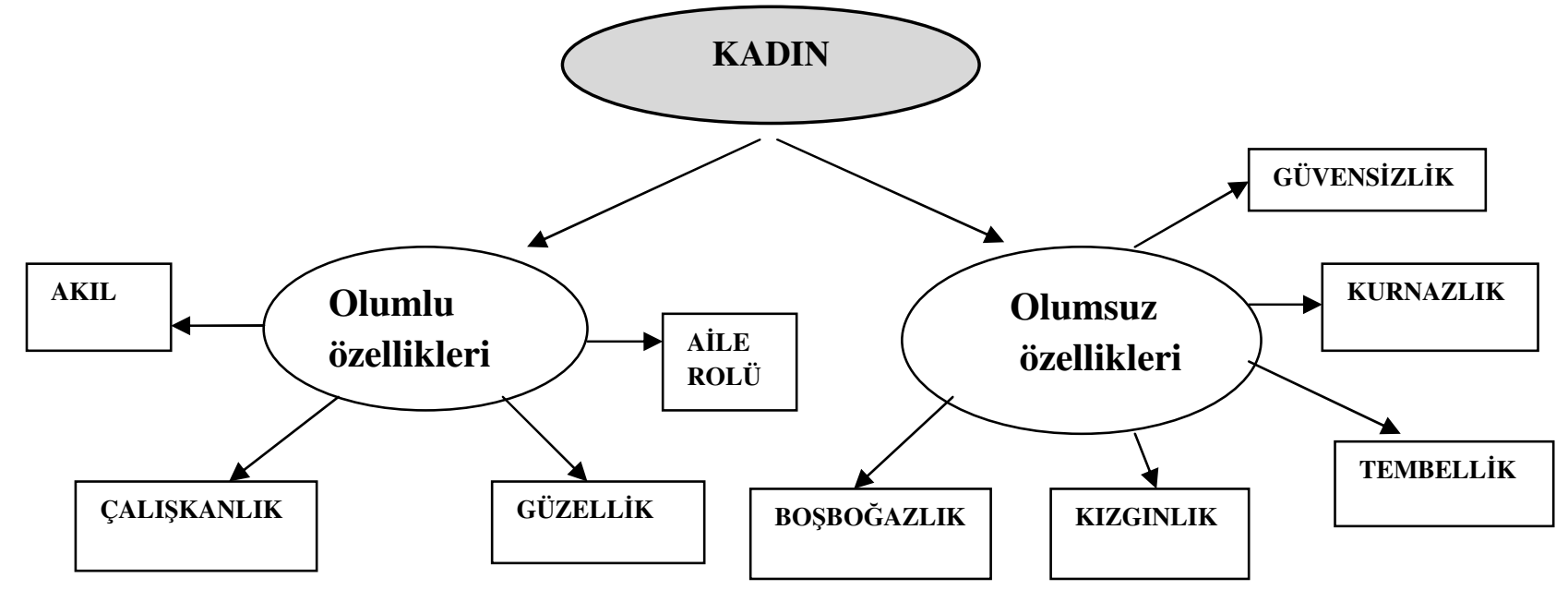

\section{Olumlu özellikleri.}

$\mathrm{Bu}$ çalışmada kadın kavramı için Kadın cinsiyetli kişi ifadesini en geniş anlamda anılmaktadır; avrat, kadın, karı, $k i z$.

Ukraynadaki atasözleri ve deyimlerin çoğu kadınların görünümünü her zaman olumlu açıdan yansitılmaktadır.

\section{GÜZELLİK}

Deyimlerin çoğu kadının güzelliğini tarif etmektedir. Fakat böyle deyimler iyi anlamda kullanılmaktadır. (Slav ülkesinden olan Ukrayna dada güzellik ön plandadır )
Bitki adlarıyla yapılmış halk atasözleri.

Ukraynadaki kadının güzelliğini halk deyimlerinde bitki ve ağaç adlarıyla tarif edilmektedir.

Gelincik gibi güzel bir kız. (Гарна дівка, як маківка).

Kartopu ă̆acl gibi güzel bir kız. (Гарна дівчина, як калина).

Kartopu ă̆acı gibi güzel bir kız, gözleri kömür gibidir. (Гарна дівчина, як калина, очі як вуглини).

Meyva gibi güzel bir kız. (Гарна дівчина, як ягідка).

Gül gibi güzeldir. (Гарна, як рожа).

Ciçek gibi güzeldir. (Гарна, як чічка). 
Ilkbahar çiçeği gibi güzel bir kız. (Гарна дівчина, як квітка навесні).

Elma ă̆acı çiçeği gibi güzel. (Гарна, як яблуня в иввіту).

Yıkamıs turp gibi yuvarlak ve beyaztenlidir. (Кругла ma біла, як мита редька).

Bașak gibi etlidir. (Повна, мов колосок).

Pişmiş kiraz gibi etlidir. (Пишнотіла, як спіла черешня).

Meyva gibi kırmızıdır. (Рум'яна, мов ягідка).

\section{Doğa adlarıyala yapılmış halk atasözleri.}

Ilkbahar gibi güzeldir. (Гарна, як весна).

Ylkamıs günes gibi güzeldir. (Гарна, як вмите сонечко).

Mehtap ylldızı gibi güzeldir. (Гарна як зоря на небі).

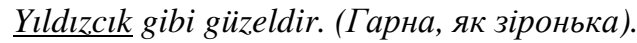

Ukrayna milleti her zaman dinine değer veren bir toplum olmuştur. $\mathrm{O}$ yüzden kadın güzelliğini pozitiv açıdan göstermek için ilahi isimlerde kullanılmaktadır.

\section{Ilahi adlarıyla yapılmış halk atasözleri.}

Tanrıça gibi güzel bir kızdır. (Гарна дівка, мов богиня).

Melekçik gibi güzeldir. (Красива як янголятко).

Melekçik gibi sevimlidir. (Мила, мов ангелятко).

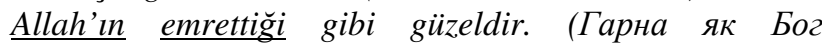
приказав).

Ukraynadaki deyimlere göre kadınların güzelliği kocasının davranışına bağlanmaktadır;

Iyi kocayla kadın Paskalya yumurtası gibidir.(3a добрим чоловіком і жінка, як писанка). Ukraynadaki el sanatında Paskalya yumurtalari çok güzel ve nefistir.

\section{AKIL}

Ukraynada ki atasözleri de ve deyimlerde kadınların aklı az tarif edilmektedir.

Negatif anlamında şöyle deyimler vardır;

Saçı иzun, aklı kisa. (У жінок волосся довге, а ум короткий. Жінки довге волосся мають, та розум короткий).

Başında tınaz, kendisi ise düve gibidir. (На голові копиия, а сама як телиия).

Ancak şunu da eklemek istiyorum; Ukraynada ki zihniyet anaerkil tarzında oluşturulmuştur, bu nedenle Ukrayndaki atasözleri ve deyimler çoğunlukla kadın aklına saygı göstermektedir; Bazen kadından akıl ödünç almak gerekir. (Часом і в жінки варто розуму позичати). Kadın tavsiye için, kaynana selam için, annem dünyadan daha iyidir. (Жінка для совіту, теща для привіту, матінка рідна лучче всього світу). Biz dünyayl yönetiyoruz kadınlar ise bizi yönetiyorlar. (Ми керуємо світом, а жінки керують нами).

İncelenen malzeme tarafından gösterildiği gibi Ukrayndaki kültürde kadının güzelliği her zaman zekasıyla ilgili değildi. Güzel kadına bakmak hoştur, akıllı kadınla ise yaşamak iyidir. ( На красиву жінку приємно подивитися, а з розумною - добре жить.) Akıllı klz arkadaştan daha iyi arkadaş yoktur. (Нема кращого друга, як розумна подруга.

\section{AILE ROL ̈̈}

Bir taraftan Ukraynadaki atasözleri ve deyimler ailenin içindeki kadının önemli rolünü yansıtmaktadır; kadınsızlık ellerin olmamasl gibidir. (Без жінки - як без рук). Kadınsız erkek - kuyruksuz hayvan gibidir. (Без жінки мужчина - як без хвоста скотина) Kadınsız erkek kedisiz gibidir. ( Без жінки як без кішки). Kadinsiz akılsiz gibidir. (Без жінки так, як без ума). Kadınsızlık kadınla uğraşmaktan daha zordur. (3 жінкою клопіт, а без жінки ще більший). İlginç bir atasözü vardır ki; Ivan plahtayı (Ukrayna Ulusal kadın giyimi, etek) taşımaktadır, Nastya ise topuzu taşımaktadır. (Іван носить плахту, а Настя булаву). Bu atasözünde kadının dominant statüsünü tarif etmektedir. Çünkü topuza her zaman iktidar sembolü olarak bakılmıştır.

Ama başka taraftan kadının ikincil rolu, erkek bağımlılı̆̆ını göstermektedir; Saksağan beyazlaştığında kadın erkekten daha büyük olacak.( Отодi жінка буде стариа, як сорока побіліє). İnek ӧkӥze nasıl yaşamayı anlatırsa bu avluya yazıklar olsun. (Горе дворові, де корова розказуе волові). Kadının ailenin rolu her zaman stereotip kadın ev ateşi bakıcı olarak yansıtmaktadır; Adam rüzgar kokusu olmalıdır, kadın ise ev kokusи olmalıdır.(Від чоловіка повинно пахнути вітром, а від дружини домом). Kadın evin üç açısını tutar, erkek sadece birini tutar. (Жінка за три угли хату держсить, а чоловік за один). Еv yeryüzünde durmamaktadır kadınin üstünde durmaktadır. (Дім держиться не на землі, а на жіниі).

\section{CALISKANLIK}

Ukraynadaki atasözleri ve deyimlerde kadının çalışkanlığ pozitif olarak yansıtmaktadır. Arl gibi çalışkandır. (Роботяща, як бджілка). Yaşlı adam yaşlı kadını iyi borş̧ hazırladı̆̆ için övüyor. (Старий стару хвалить, щэо добрий борщ варить).

Sincap gibi çabuktur. (Моторна як білка).

Olumsuz özellikleri. Ukrayna zihninde kadın çeşitli günahların taşıyacası olarak yerleşmiştir.

\section{BOŞBOĞAZLIK.}

Boşboğazlık kadının olumsuz eksiklerinden biridir. Kadınların dili kürek gibidir. ( В баби язик, як лопата). Kadınlar saksağanlar gibidir. ( Жінки, як сороки). Kadınların güсӥ dilindedir. (Жіноча сила в язиџі). Kadın kadının kulağına konuşmuş, fakat bütün köy duymuş. (Бабa бабі говорила на вухо, а все село чує). Iki kadın-pazarllk, üç ise pazardır. (Дві баби - торг, а три - ярмарка) Iki kadin ve iki kaz pazardır. ( Як дві баби та гуска, то весь базар) Pazar, pazarlık ve fuar gürültüsü semboller ve kadın çatışma davranışın da semboldur.

\section{GÜVENSIZLLIK.}

Sadece Ukraynada değil çok halk bilincinde kadına güvenmemeye ikna olmuştur. Kadına bütün doğruyu açma. (Жінці всієї правди не одкривай). Kadınа vе рараzа doğrи söyleme. (Жіниі та попу правди не кажи). Kadına doğrи söyleme, özge çocuğu alma, zenginlerle kardeşleşme. (Жiнuฺi правди не кажи, чужої дитини не бери, з панами не братайся). Hiçbir zaman kadına doğru söyleme. (Ніколи жінщі правди не кажи). Kadına doğrи söyleme, papazdan borç alma.(Жіниі правди не кажи, у попа грочей не позичай). Kadına doğrи sorma. (У жінки правди не питай).

\section{KIZGINLIK}

Ateşten sulardan ve klzgıı karıdan Allah korusun( Bid огня, води і злої жони, Боже, борони).Kızgın karıdan 
yaşlanacaksın, iyi karıdan gençleşeceksin. (Від злої жінки постарієш, а від доброї- помолодієш). Genç ısırgan gibi iyidir. (Добра, як молода кропива) Isırgan gibi acıklıdır. (Жалка, як кропива). Kuzukkulağı gibi tatlıdır. (Солодка як кисличя). Yılan gibi karıcı.. (Жонка, як змія) Yılan gibi kızgındır kadındır.(Жінка зла, як зміюка). Kızgın kadın sanki yedi zehir pudu ${ }^{l}$ dilinin altındadır. Зла жінка, наче сім пудів яду під язиком). Turnabalı̆̆ gibi kızgın kadındır. (Зла, як шука). Cadi gibi kızgındır. (Зла, як відьма). Çаlının altındaki yılan gibi kızıındır. (Зла, як гадина під корчом). Kızgın kurk gibidir. (Сердита, як квочка).

Iyi kadın düğündür, kötü kadın zehir iksiridir. (Добра жінка - то весілля, а зла - то погане зілля). Iyi kadın bu düğün gibidir, neseli, mutlu, sevinçli, kızgın kadın ise zehir iksirine benzer, yani zehirli, kötü ve zararl1.

\section{KURNAZLIK}

Ukraynadaki atasözleri ve deyimlerde bir daha olumsuz kadının özelliğini vurgulamaktadır.

Tilki gibi kurnaz kadın.(Баба хитра, як лисиия). Tilki veya şeytan gibi kadındır.(Баба, як лисиия або чорт). Kadın şeytandan daha kurnazdır.(Жінка хитріша від чорта) Şeytan bir işi yapamazsa o zaman oraya kadını gönder. (Де чорт не зможе, туди жінку пошли). Kadınla ile şeytan davay kaybetmişti. (3 бабою $i$ дідько справу програв). Kadın şeytanı aldatacak.( Баба й чорта зведе).

\section{TEMBELLIK}

Kurk yumurtaları üstünde gibi uzun uzun kalmıştı.(Засиділась як квочка на яйцях).

Kadın - prenses , ama evi süpürmemiştir. (Жінка княгинька, а хата-неметена).

Kurk yumurtaların üstünde gibi oturur. (Сидить як квочка на яйцях).

İncelenen Türk atasözleri ve deyimlerde kadın kavramı çok net bir şekilde bu diyagramda yansıtılmaktadır.

Türk halk atasözlerinde kadın görüntüsü aşağıdaki kritirlere göre sınıflandıralabilir.

\section{Olumlu özellikleri.}

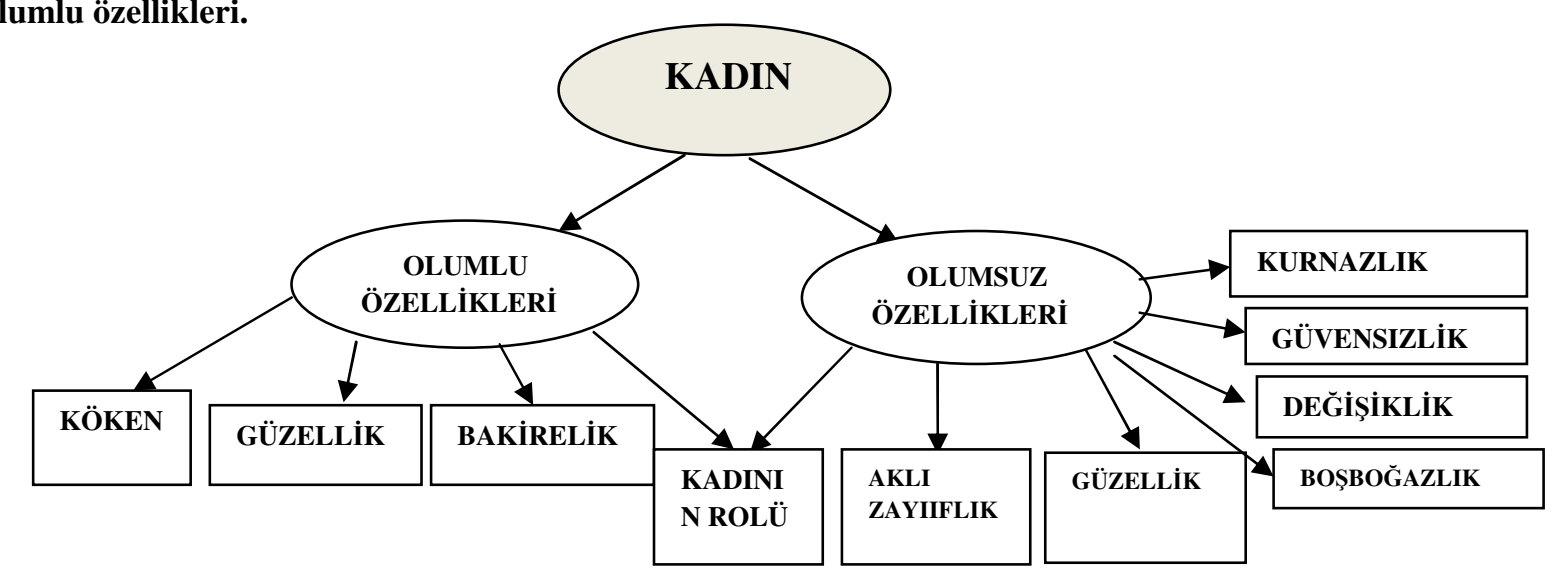

\section{KÖKEN.}

Türk toplumu aşağıda bazı örneklerdede belirtildiği gibi kızın kökenine yani soyuna oldukça önem verdiği anlaşılmaktadır

Alma delinin kızını soya çeker.

\footnotetext{
${ }^{1}$ Pud - 16, 38 kiloya eşit ağırlık birimi.
}

Ana ile kız, helva ile koz.

Ananın çıktı̆̆ dala kızı salıncak kurar.

Anasına bak, kızını al, kenarına bak bezini al. Annenin bazı huyları kızına geçer.

Anasının kızı. Huy tutumu anasına benzeyen.

Anasının edirdiği babasının doğurduğu. Geleneğe uygun yetişen.

At alsın başlıdan, kız alsın çarlıdan.

Bez alirsan Musul'dan, kiz alırsan asilden.

Çobana verme kızı ya koyun gütürür ya kuzu / Lafin azı, uzu cobana verme kızl, ya koyun gütürür, ya kuzu.

Pekmezi küpten, al kadını kökten al.

Tatlıyı küpten almalı, kadınlığı kökten.

\section{GÜZELLİK}

Ihlamurdan odun olmaz beslemeden kadın / Gül dalından odun beslemeden kadın olmaz.

Çirkin ile bal yeme, güzel ile taş taşı.

Güzel bürünur, çirkin görünür.

Güzele bakmak sevaptir.

Güzele ne yakışmaz.

Güzel nerede, kavga orada.

Güzeli güzel diye sevmeli çirkini Allah için sevmeli.

Er kemaliye avrat cemaliyle antlur.

Her güzel güzeldir ama canın sevdiği daha güzeldir.

\section{BAKİRELIK}

Tarlayı düz, kadını kız al. Tarla alacak kimse, düz yerden almalı; bayırdan, engebeli yerden almamalıdır. Evlenecek erkek de dul kadını değil, kızla evlenmelidir.

\section{KADININ OLUMLU ROLU}

Erkek aslan dişisine bakar da kuvvet alır.

Evi ev eden kadındır.

Iyi ipek kendini kırdırmaz, iyi kadın kendini dövdürmez.

Evi ev eden avrat, yurdu şen eden devlet.

Bir adamın karısı o adamın yarısıdır. Erkek kadınıyla daha güçlü olur.

Kadın erkeğin eşi, evin güneşidir. 
Kadını erkek değil, ar ve namus korur.

Kadın topraktır.

Kadın kadıncık. Evinin eşini beğenilecek biçimde yapan dikişeni bilen temiz giyinip ev hanımı.

\section{Olumsuz özellikleri}

Kadınlar birçok ülkenin atasözlerinde genelde erkeğe göre arka planda kalmış ve olumsuz yönleriyle verilmeye çalışılmıştır. Kimi atasözü ve deyimde kadın kötülüklerin kaynağı ve uzak durulması gereken bir varlık olarak tasvir edilmekte; kadının kurnazlığı yaptığı bu kurnazlıklarla da erkekleri yendiği belirtilmektedir. (Batur,2011:579).

\section{KURNAZLIK}

Kadın erkeğin şeytanıdır. Erkekleri kadınlar yoldan çıkar. Kadının fendi erkeği yendi. Kadınlar kurnazlıkta erkeklerden üstündürler.

Anasının gözu. Çok kurnaz, hileci olmak.

Anasının ipini satmış. Kendisinden her türlü kötü iş beklenen olmak.

Kadın şeytana pabucunu ters giydirir.

Kadın şerri şeytan şerrine eşittir.

\section{GÜVENSİLIK VE BOŞBOĞAZLIK}

Art sirrl, karl sirri.

Avratla atı emanet deme.

At ile avrata inan olmaz.

Avratla oğlana sırrını deme. Kadın güvenilmez oğlundan sir verilmelidir.

At ile avrada güven olmaz.

Kadının söylediği kırk sözden sadece birine inan.

Kadına, çocuğa, sarhoşa sırrını açma.

Kadınların işi tavukların eșinmesine benzer.

Kadınlar hamamına dönmek. Herkesin birden konuştuğu çok gürültülü ortam durumuna gelmek.

Kadında vefa, borçluda şefa aranmaz.

Kırk yılda bir kadının sözü dinlenmelidir.

\section{GÜZELLIK}

Çirkin karl evi toplar güzel karı düğün gezer.

Güzelim diye mağrur olma tez geçer vakti sebap.

Güzele kırk günde doyulur, iyi huya kırk yılda doyulmaz.

\section{AKLI ZAYIFLIK}

Alma delinin kızını soya çeker.

Avradın sacı uzun olur, aklı kısa.

Deli kız deli gelin olur.

Deli kız evde kalmaz, delikli boncuk yerde kalmaz.

Delikli boncuk taş yerde durmaz kız kısmı evde kalmaz. (deli kız evde kalmaz)

Gökyüzünde düğ̈̈n var deseler kadınlar merdiven kurmaya kalkar. Kadınlar, düğune, eğlenceye can atarlar. Bu uğurda katlanmayacakları sıkıntı yoktur.

Kadının kısmı saçı uzun olur, aklı kısa / Kadının saçı uzun aklı kısa.

Kadının cahilin sofusu şeytan maskarası.Cahil kadınla şeytan alay eder. Böyle kadınlar evlerini ihtimal ederler. Biçimsel ibadetleri yüzünden gerçek ibadetlerini yapamazlar.

Ama Türkçe' de tam tersi de atasözü vardır: Kadının zoru diline küvvet.

\section{KADININ ROLU.}

Türk atasözleri ve deyimlerde kadının rolu binardır. Bir atasözü ve deyime iki zıt kadının rolu yansitılmaktadır.

Kadın vardır vezir eder, kadın vardır rezil eder. Kadın kocasını yüceltebileceği gibi çok zor durumlara da düşebilir.

Kadın kocasını isterse vezir, isterse rezil eder. (Kocasını vezir eden ile rezil eden de karısidır.)

Avrat var, arpa unundan aş yapar, avrat var, buğday unundan keş yapar.

Iş bilen kadın, elverişsiz gereçle güzel şeyler meydana getirir. İş bilmeyen kadın ise en iyi gereci kullansa bile bir sey yapamaz.

Avrat var ev yapar, avrat var ev yıkar.

Ailede kadının rolu cok önemlidir. Öyle kadınlar vardır ki bir aileye düzen verir, mutluluk getirirler. Öyle kadınlar vardır ki ailenin düzenini, mutluluğunu bozarlar.

Eti ciğer eden de avrat, ciğeri et eden de. Beceriksiz kadın, pahalı malzemeyi heder eder; becerikli kadın ucuz nesnelerle güzel şeyler yapar.

Ama genellikle Türk atasözü ve deyimlerde kadının olumsuz ya da ikincil rolunu dikkatımız çekmektedir.

Kadının şamdanı altın olsa mumu dikecek erkektir. Kadın ne denli bol, değerli ceyizle gelirse gelsin evin bütün eksiklerini erkek sağlar; giderlerini erkek karşılar; evi o geçindirir.

Kadın kısmı kara yazılıdır.

Kadın var kardan soğuk kadın var kordan sıcak.

Karı ile çıkma yola, başına gelir türlü bela.

Kızın var, sizın var.

\section{Sonuç}

Yukarida yazılan bildiri Urayna ve Türk toplumlarının kadınla ilgili atasözleri ve deyimlerinin bir çözümleme denemesidir.Yazıdan da anlaşılacağı gibi Türk ve Ukrayna toplumlarının kadına olan bakış açısının farklı olduğu görülmektedir.

Ukraynadaki atasözlerin ve deyimlerin olumlu özelliklerine rağmen olumsuz özellikleri de ön plana çıkmıştır. Fakat Ukrayna'da kadınların zekası ve ailedeki önemli rolünü atasözlerine ve deyimlerine önemli ölçüde yansıtmıştır bunun sebebi de Ukrayna da eski zamanlardan beri ana erkil olarak kadın görlmüştür.

Slav ülkelerinden sadece Ukrayna'da kadınların çeşitli sebeplerden dolayı kocalarını dövdüğü bilinmektedir ve hatta bunu geçmişten günümüze gelen bir çok şarkıda dile getirilmiştir.

Türkiye'de ise yukarıda açıkladığım gibi olumlu özellikler ne kadar çok olsa bile olumsuz özellikler daha çok ön planda tutulmuştur. Meselâ kadının tehlikeli kurnaz güvenilmeyen akılsız gibi yakıştırmalar ile atasözleri ve deyimlere yansıtılmıştır.

Yazıdan da anlaşıldığı gibi her iki ulusunda kadınların olumsuz özelliklerine daha çok vurgu yapılmıştır.

\section{KAYNAKLAR}

Aksan, Doğan (2007), Her Yönüyle Dil Ana Çizgileriyle Dilbilim, Türk Dil Kurumu Yayınları, 439 s., Ankara.

Aksoy, Ömer Asım (1995), Atasözleri ve Deyimler Sözlüğü, İnkılâp Yayınevi, 392 s., Ankara

Çobanoğlu, Özkul (2004), Türk Dünyası Ortak Atasözleri Sözlügü, Ankara:AKM Yayınları, 511+VIII s., Ankara. 
Eşkenov, Döölötbek (2007), Türk ve Rus Atasözlerinde Kadın Imajının Dilbilimlik Karşılaştırması. Yayımlanmamı̧ Yüksek Lisans Tezi, Bişkek.

Korkmaz, Zeynep (2010), Gramer Terimler Sözlüğü, Türk Dil Kurumu Yayınları, 575s., Ankara.

Coates, Jennifer. (2004), Women, men, and language: A sociolinguistic account of gender differences in language, Pearson Education, $225 \mathrm{~s}$. 